\title{
Eco-labeling of electricity — strategies and tradeoffs in the definition of environmental standards
}

\author{
Bernhard Truffer ${ }^{\mathrm{a}, *}$, Jochen Markard ${ }^{\mathrm{a}}$, Rolf Wüstenhagen ${ }^{\mathrm{b}, 1}$ \\ ${ }^{a}$ Swiss Federal Institute for Environmental Science and Technology (EAWAG), Limnological Research Centre, CH-6047 Kastanienbaum/Switzerland \\ ${ }^{\mathrm{b}}$ Institute for Economy and the Environment, University of St. Gallen (IWOe-HSG), Tigerbergstrasse 2, CH-9000 St. Gallen/Switzerland
}

Received 4 December 2000

\begin{abstract}
The liberalization of electricity markets opens up new opportunities for electricity providers to differentiate their products along environmental characteristics. Due to considerable search and evaluation costs for the consumer, the success of green power products depends to a large degree on a professional communication strategy. Besides professional marketing, instruments like environmental labeling have attracted considerable attention. The present paper analyzes the fundamentals of voluntary, third-party eco-labeling of electricity products and compares different labeling approaches, which have been developed in Europe and in the US recently. We distinguish six major dimensions along which labeling schemes can differ and identify two main strategies to deal with the basic tradeoffs, correspondingly. Labeling concepts may either be simple, require low or medium environmental standards and strive for the support of at least one stakeholder group. Alternatively, eco-labels may judge a broad range of environmental impacts and integrate several stakeholder groups with opposing interests. Experiences show that labels of the first type can be set up quickly and have the advantage to set a standard early in the market. In the medium and long term, however, public awareness and potential criticisms may rise and rather simple eco-labeling schemes will have to be adapted. The paper finally discusses the prospects for a common European eco-labeling strategy. (C) 2001 Elsevier Science Ltd. All rights reserved.
\end{abstract}

Keywords: Environmental labeling; Green power; Electricity Marketing

\section{Introduction}

The structure of electricity markets is undergoing profound changes in many countries of the world. Liberalization leads to increased competition among producers (Loskow, 1998) and consumers may now choose among a range of differentiated products. The net effect of these transformations on the environment, in general, and renewable energy, in particular, is yet to be determined (Schelling, 1998). Increased cost pressureparticularly in a situation where external costs of conventional power generation are not sufficiently internalized - makes it more difficult for emerging renewable technologies to compete in the market. However, recent experience shows that many customers are willing to pay

\footnotetext{
*Corresponding author. Tel.: + 41-41-349-2111; fax: + 41-41-3492162.

E-mail addresses: truffer@eawag.ch (B. Truffer), markard@eawag.ch (J. Markard), rolf.wuestenhagen@unisg.ch (R. Wüstenhagen).

${ }^{1}$ Tel.: + 41-71-224-2739; fax: + 41-71-224-2722. http//www. oekostrom.eawag.ch. http://www.iwoe.unisg.ch/institut/rwu.htm.
}

more for renewable energy. Green power products, i.e. electricity offerings, which are based on environmentally preferable energy sources, are gaining importance in electricity markets worldwide. They show that customer demand for green electricity may be an important driving factor for supporting environmental sustainability in a liberalized market. The success of green power products depends to an important degree on a professional communication strategy. Besides establishing specific marketing strategies for green power products, transparency-enhancing instruments like environmental labeling may be decisive.

The present paper focuses, both theoretically and empirically, on the analysis of third party eco-labels for electricity. Third-party environmental labeling programs are carried out by an independent body, whereas firstparty labeling is performed by marketers on their own behalf (EPA, 1998). In the following, we concentrate on voluntary certification schemes and we will use the short form eco-labeling mainly. What seems, at first hand, a simple problem of putting a tag on an electricity bill, leads quickly to a host of highly complex issues: which 
environmental standard should be chosen as a benchmark? How many and which environmental impacts should be considered? How will the ultimate environmental benefits of a green power purchase be assessed and signaled to the customers? By analyzing and comparing some major green electricity labels, which have recently been launched, different strategies for responding to these questions can be identified. The aim of the paper is (i) to provide a fundamental assessment of developing ecological product standards in the electricity market and (ii) to draw future perspectives for green electricity labeling.

We will, however, not discuss the more fundamental issues like (i) the role of third-party eco-labeling in the concert of environmental policy instruments, (ii) the ecological effectiveness of eco-labeling (Salzman, 1997) or (iii) strengths and weaknesses of labeling in general (Morris, 1997). We state that the green power market is one important means to promote renewable energy but will not be sufficient to bring about a sustainable electricity future by its own (Jegen and Wüstenhagen, 2000). From this point of view, eco-labeling can be a promising tool to support green consumerism but always has to be regarded in the concert of energy policy instruments.

In the following section, we will describe first the preconditions of a professional product differentiation strategy both from a producer's and a consumer's point of view. Section 3 discusses different means to reduce transaction costs for the market actors. Special emphasis will be laid on the role of third-party eco-labeling. In Section 4, the fundamental functions of an eco-label, namely the consideration of costs, the definition of what might be "environmentally preferable" and the transfer of "credibility" to the labeled products will be analyzed. In Section 5 this leads to the comparison of different ecolabeling approaches, in Europe and in the U.S. We will conclude with an outlook on the future development of labeling initiatives in Europe and world wide.

\section{Differentiating electricity along environmental dimensions}

From a competitive strategy point of view, companies in a liberalized electricity market can basically choose between two of Porter's (1980) generic strategies, namely cost leadership or differentiation. To improve their competitive position, they can either try to achieve lower costs than their competitors or establish a unique selling proposition, which allows them to charge customers a premium and hence increase revenues.

\subsection{Marketing challenges for electricity providers}

To differentiate from its competitors, a company has to identify characteristics of its product, which make a relevant difference to the consumer, and take this as a foundation for its marketing strategy. This is a relatively new approach in the electricity industry, but it is of course everyday business in almost any other industry. Global brands like McDonalds, Coca Cola, Heineken, American Express, Evian or Nescafe have demonstrated for a long time how differentiation can increase returns in otherwise homogeneous markets. In the case of electricity there are several features that may serve as a basis for differentiation:

- technical features (e.g. availability at peak load times, reliability),

- customer segments (e.g. offerings for small and medium enterprises like bakeries),

- additional services (e.g. energy efficiency advice, online billing) or

- environmental characteristics (e.g. renewable, low air emissions, nuclear free).

The latter seems particularly promising from an energy policy point of view, as it might be a means to get customer preferences in line with societal needs. There are some indications that green power offerings can be a viable option for electricity providers. One is that opinion polls and market research in many countries show that customers state clear preferences and an associated willingness to pay for renewable energy sources. As a general rule these studies indicate that about $20 \%$ of the households are willing to pay a price premium of $10-20 \%$ on their electricity bill for environmentally preferable electricity (Farhar, 1999). Empirical data from liberalized markets show that the actual customer response to green power offerings is initially lower than these surveys propose (Wüstenhagen, 2000; Fouquet, 1998), with market shares often below $1 \%$

The second indication is the experience of other industries. For example, recent years have shown a significant success in green marketing in the food market. The No. 2 Swiss food retailer, Coop, is one of these success stories (Villiger et al., 2000). ${ }^{2}$ Having embraced an ambitious green marketing strategy in 1993, Coop's sales in organic food products have grown within 6 years from zero to CHF 500 million (approx. 300 Mio Euro) in 1999, and the company's stated goal is to double this figure over the coming years. The comprehensive green marketing strategy has also helped the company to significantly increase its share in the saturated Swiss food market against its prime competitor, Migros.

The experience of food marketers as well as early empirical evidence from the green power market indicate

\footnotetext{
${ }^{2}$ Successful green marketing strategies can be identified in other countries as well, such as the organic product range of Sainsbury's in the UK or Wholefoods Market, a retailer specialized on organic food, in the US.
} 
that some particularities should be taken into account when designing a green power marketing strategy (Wüstenhagen, 2000; Holt, 1997a). In order to capture not only the small niche of highly environmentally aware customers (the "Trueblue Greens" as referred to by Roper Starch Worldwide, 1998), the marketing mix has to be carefully balanced between environmental performance, economic constraints and the customers' preferences. Customers want to purchase a product that is environmentally preferable and has a good public reputation at the same time. Furthermore, green power products have to be convenient, i.e. readily available and easy to purchase with regard to metering, billing or the change of supplier, and the green supply contracts should be likely to cover $100 \%$ of the customer's electricity demand. $^{3}$

The pricing of green power products should be in a reasonable range compared to conventional products, e.g. $10-30 \%$ above the price for conventional products. A range of products with differentiated prices helps to meet the varying willingness to pay of different customer segments. Communication is another essential element of the green power marketing mix. Professional promotion usually means higher budgets, but beyond mere advertising, personal communication with the customer via call centers or the internet is important, too.

Marketing theory providers the key to deal with most of the mentioned success factors. Currently marketing is a rather new field in electricity markets and product differentiation for environmentally preferable goods is an uncommon field of activity. Improving the professional quality of marketing activities may therefore considerably enhance the prospects of green power markets (Wüstenhagen, 2000).

Apart from that, providers of green goods have to face another major challenge, which is related to the credibility of their offerings. Unlike short-term marketing targets like increasing brand awareness, building up credibility is much less under the control of the individual firm and depends on the interplay between different market actors and stakeholders.

\subsection{Information problems for green power consumers}

The issue of credibility is closely related to the customer's purchasing motives for environmentally friendly products. Until very recently, electricity had not been perceived as a commodity and there had not been any opportunity to express specific preferences either.

\footnotetext{
${ }^{3}$ Some green pricing programs just raise premiums on the regular electricity bill thereby contributing into a green electricity fund. Although customers support environmental friendly energy sources in this case the electricity delivery contract is still based on conventional power (e.g. see Future Energy, 1999).
}

From an individual consumer's perspective the decision in favor or against a green electricity product is ridden with some major difficulties. Environmental and social benefits have the particularity that they accrue to the society at large, whereas the costs for the products fall on the green consumer. Why should a rational individual have an increased willingness to pay for these products? Some consumers may be motivated to improve their individual environmental impact record by consuming "clean" electricity. Business customers will probably consider this effect in terms of improving their environmental image. Some motives of households may be identified as forms of impure altruism (e.g. feelings of warm glow, cf. Oberholzer-Gee, 2000). Beyond this, more socially relevant motives may exist: either there might be the conviction that someone has to take the lead for compensating for market failures (De Jasay, 1989) or that immature technologies need an initial push to become competitive because of substantial technological advances.

Given a certain distribution of the people in the population, which express an increased willingness to pay based on the above-mentioned motives, the resulting market potential might still not be realized because of high transaction costs the consumer is confronted with. Transaction costs may occur with regard to the purchasing decision, as environmentally friendly goods are usually difficult to evaluate from a customer's point of view (Haberer, 1996). In the case of green electricity, customers would have to invest considerable effort and time in order to

- obtain credible information about a product's environmental characteristics,

- evaluate a product's ecological impacts and

- compare different products.

To avoid transaction costs, customers may also choose to rely on the environmental marketing claims of green power providers. This option will highly depend on the credibility of a particular offering and the image of the supplier, respectively. Given the difficulty to verify the marketing claims, this may not prevent the customer from picking a low-quality product. In this situation of quality uncertainty, choosing a low-cost product may be the best way for the customer to avoid risk. The information asymmetries between the green power producer and the customer are likely to cause withdrawal from more expensive, high-quality products. Thus environmentally preferable products may eventually be crowded out of the market (cf. the phenomenon of adverse selection, Akerlof, 1970).

\section{Enhancing transparency in green electricity markets}

Several means for reducing information problems have been described in the literature (see Russel, 1998; EPA, 1998; Holt, 1997b). For the green electricity market, the 
following strategies merit some attention: screening, signaling, disclosure standards and third-party eco-labeling.

Screening is a solution strategy for the less informed economic actor, i.e. the individual consumer. He tries to get a better understanding about the electricity offerings by using secondary, aggregated information. The information may stem from consumer organizations, specialist journals or from experienced friends and relatives. Signaling relates to the better informed actor, i.e. the producer who can emit signals for product quality in order to convince the customer. Costlier signals tend to be more credible because they are more difficult to be imitated by competitors who offer low-quality products. In the case of green power, the installation of new, costly generation plants like wind turbines may serve as an example. ${ }^{4}$ Moreover, companies can invest into their public image as a trustworthy and reliable promoter of environmentally and socially responsible products through sponsoring, advertising and the like. However, such a strategy is likely to be a long-term endeavor.

Alternatively, legitimacy and credibility can be transferred from other actors, which are considered as trustworthy by the relevant consumer segments. One possibility is the implementation of a disclosure standard, i.e. a declaration of the content of the respective product. In the case of electricity the declaration may include a disclosure of power source and fuel mix, air emissions, price and contractual terms. Uniform and trustworthy disclosure can be seen as a basic prerequisite for green electricity markets to develop. Consumers are, in principle at least, empowered to make their purchasing decisions based on their preferences (Wiser, 1999; NCCEI, 1998; REA, 1998). A disclosure standard is most valuable if it is mandatory for all products in the market and not only for green power offerings.

A full disclosure of power sources is a valuable tool for consumers to get information about the available products. However, a large group of consumers might not be willing and/or able to read through all the details of a product declaration. Additionally, they may not be informed about the environmental impacts of different power sources. In order to enable low involved consumers to make informed decisions in the messy environment of a deregulated market, there is a need for higher-aggregated information and guidance. One way of providing such a guiding tool is eco-labeling.

Third-party Eco-Labels are attributed to products after having been certified to fulfill specific criteria (EPA, 1998). Compared to the disclosure of electricity products, labels normally include a specific value judgement thus implicating an explicit purchase recommendation for the

\footnotetext{
${ }^{4}$ For a more detailed description of screening and signaling with regard to the green power market cf. Markard et al. (2000a). For a general description see Haberer (1996).
}

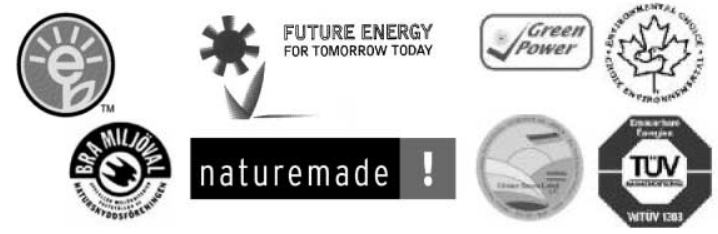

Sources: Center for Resource Solutions, Energy Savings Trust, SEDA, Sources: Center for Resource Solutions, Energy Savings Trust, SEDA,
Environment Canada, Swedish Society for Nature Conservation, Naturemade, Grüner Strom Label e.V.. TÜV Süddeutschland

Fig. 1. Examples of green electricity labels (USA, UK, Australia, Canada, Sweden, Switzerland and Germany).

labeled product. Eco-labels have been established in different product sectors (Salzman, 1997). The most popular eco-labels are of a generic kind, i.e. they apply to a wide variety of products like toilet paper, varnish or cat litter. Well-known examples in Europe are the German Blauer Engel or the European Flower. Blauer Engel has been set up 20 years ago and products from about 1000 companies have been labeled since (Umweltbundesamt, 1998). Generic labels seem to be well suited for product sectors where criteria are rather easily defined and where no controversial political conflicts exist. For more complex products, sector-specific labels have been developed. As a rule, they are tailor-made for the specific problem at hand and have been initiated by specific stakeholders in the area. The Forest Stewardship Council label for sustainable forest management is a well-known example for the latter kind (FSC, 2000). Before we describe and assess the strengths and weaknesses of different labeling approaches, we will have to analyze the structure and function of eco-labels for green electricity in more detail. Fig. 1 shows some logos of eco-labels for green electricity worldwide.

\section{Principles of green electricity labeling}

As electricity supply is a rather sophisticated issue in terms of technical, economical and ecological constraints, green electricity labeling becomes a highly complex undertaking. Experiences have shown that there is a large variety of possibilities to set up a certification scheme (Holt, 1997b). In the following, we will identify the key dimensions along which different eco-labeling approaches may be distinguished.

We mentioned before that enhancing customer information is the key function of eco-labeling. This role depends on the simplicity and market penetration of the label, which lowers the recognition effort for the consumer (cf. Section 4.1). Furthermore, the accuracy of the criteria and claims of the label have to correspond to the expectations of the consumers (cf. Section 4.2). Finally, the trustworthiness of the supporting body and the objectivity of the quality control procedures, which 
are implemented by the eco-labeling institution have to be guaranteed (cf. Section 4.3).

\subsection{Reducing transaction costs for consumers and producers}

The potential of eco-labeling to reduce transaction costs depends on whether the label is easily recognized as a trustworthy indicator by the relevant consumer segments. Single level labels will, as a rule, be easier to understand than labels with two or even more levels. Labels, which are based on simpler criteria, are easier to communicate than more complex ones. However, a label will not be accepted if it is not able to represent the environmental quality of a product in an appropriate way. So, the label is bound to deal adequately with the underlying complexity of the environmental impacts.

Recognition by consumers will, furthermore, greatly be enhanced, if the label is accepted as a standard, not only by the consumers but also by the different competitors, which offer green power products. The more the market grows, the more products will be sold with the label, the easier it will be for consumers to recognize the label and therefore to base their purchasing decision on it. Market penetration will therefore also depend on the applicability of the label for producers and traders.

Acceptance by producers is dependent on whether the benefits of using the label exceed its costs. The benefits are related to an increased willingness to pay for green products and a reduction in communication efforts because of the labels' high credibility. The costs for obtaining the label will mainly depend on the cost of gathering information in order to decide about the criteria and the measures, which have to be taken in order to fulfill the criteria. Furthermore, license fees typically have to be paid to the labeling organization.

Of considerable importance is the impact of a label on communication costs. This depends on the complexity of the label, but also to an important degree on whether or not other parties will support or contest the label. An eco-label, which will be opposed by specific environmental organizations, may eventually increase - instead of decrease - the need for communication. Alternatively, if environmental organizations support the label and advertise it to their members, a positive image transfer on the respective products may be reached at low cost (Mayer et al., 1999).

\subsection{What is "environmentally preferable"?}

Product differentiation will ultimately be based on environmental characteristics of the products. A key question every green electricity label has to answer is, therefore, how "environmentally preferable" electricity products look like. At a first glance, the answer seems simple: The consumption of electricity by a green power consumer should produce low environmental impact. The translation of this claim into operational criteria, however, proves to be far more complex.

\subsubsection{Environmental standards and completeness of the assessment}

In general, electricity products can be evaluated with regard to a selection of environmental impacts, which are associated with their generation. Their score may then be compared to either the average score of a national (or in the case of Europe UCPTE) electricity mix, or to the score of a marginal power system, which would currently be built, if additional capacity was needed (e.g. combined cycle plants). The final result will depend crucially on the completeness of the assessment, i.e. the environmental impacts selected for comparison and the applied minimum standards.

For the sake of simplicity, the assessment of environmental impacts may be reduced to some salient environmental issues. Many labels limit the eligible energy systems to renewable energy sources (RES, i.e. photovoltaics, wind, geothermal, biomass and hydropower). Electricity from RES, so goes the argument, is green because it does not use up finite resources. An alternative single criterion approach is represented by the "climate friendliness" of the products. This may be further simplified by assessing and comparing direct $\mathrm{CO}_{2}$ emissions from different power sources.

Both shortcut criteria - renewable or climate friendly - have the advantage that they are easily communicated and understood by the customers. From an environmental point of view, however, a focus on mere fuel-based criteria seems incomplete. A more thorough approach has to assess emissions on the basis of an encompassing life cycle assessment (LCA). Some labels therefore benchmark their products against the normal electricity mix by using integrated life cycle methods, like the Eco-Indicator (Frischknecht and Jungbluth, 2000; Goedkoop, 1995).

Even though life cycle assessment aims at considering the entirety of the environmental impacts of a product, some issues are difficult to handle. This is true for the majority of those impacts, which vary considerably from plant to plant and which are strongly related to the location specific characteristics of a plant. Impacts on landscape or ecosystems fall under this category. A way of dealing with these problems is to accept only plants, which fulfill a minimum standard at the local level. ${ }^{5}$

\footnotetext{
${ }^{5}$ These problems are especially relevant in the case of hydropower but also for some types of power plants using biomass or wind energy. As a consequence, some eco-labeling schemes have set up particular, locally adapted assessment procedures for hydropower or, in the case of biomass, are restricted to organically grown crops or FSC-certified firewood. Another example are wind farms, which should not be built in passage corridors for migrating birds (for further details see Section 5).
} 
Finally, one might argue that given the broader set of goals implied by sustainable development an even more encompassing approach would be needed. To assess the sustainability of energy products, a label should incorporate social and economic impacts as well. Such an attitude is represented in the claim that the most sustainable $\mathrm{kWh}$ of electricity would be the one that did not have to be produced by any generating capacity (the "negawatt", cf. Lovins et al., 1999). According to this, green electricity products should only be labeled if they are part of a more encompassing energy savings service package.

The mentioned approaches to define green electricity have the fact in common that they endeavor to assess environmental product quality in a more or less objective way. However, in order to be understood and accepted in the market, a label must also respond to the subjective perception of power systems by the customers. For example, solar power is perceived as environmentally cleaner than combined cycle plants by a majority of customers, despite the fact that inefficiencies in today's PV manufacturing processes might make this technology score lower in a life cycle assessment than combined cycle plants. Such differences in scientific assessment versus lay man's perception give rise to tradeoffs that have to be carefully dealt with. Neither sticking to scientific assessments only, nor opportunistically following customer perceptions will provide a satisfying answer. For this (and other) reasons, critical voices fundamentally reject the concept of eco-labeling as such (cf. Morris, 1997).

The choice of evaluation criteria is a matter of costs too. A comprehensive and complex assessment procedure will increase the development costs of a label as well as expenses for certification later on. Moreover, it may lead to an increased need for communication in order to make the customers understand the label. On the other hand, if a reduced criteria set is chosen, the label may be accused to promote environmentally dubious forms of power plants. The problem of labeling hydropower may be illustrative in this context. Although hydropower scores extremely high on most LCA measures, it is - in some countries at least - strongly opposed by local environmental groups and a further expansion of power plants would be perceived as severely damaging to the environment. Several labels have tried to solve this problem by either accepting only small or already existing hydropower plants. However, from an environmental point of view this strategy proves to be essentially meaningless and does not solve the problem of the criticisms (Markard et al., 2000b).

A final tradeoff lies between the market penetration of the label and its credibility. This is reflected in the decision about the level of the minimum environmental quality, a product has to reach in order to be eligible for the label. If this level is relatively low, labeled products may spread in the market more easily. If the level is relatively high, then the label might have higher credibility, but its application will be restricted to a smaller number of products. One possible solutions to this tradeoff is a multi-level label with a differentiation in the environmental quality of the products.

\subsubsection{Promotional effects}

Given the complexity of assessing the environmental impacts, one might argue that customers are ultimately not very much interested in a thorough evaluation of existing plants. Rather, they want to improve the environmental situation associated with their electricity consumption (Markard, 1998). Therefore, the label has to guarantee that additional green generation capacity is connected to the grid and that less desirable plants will be disconnected as a consequence. Today, the existing power supply from RES already exceeds the actual demand for green power products in most electricity markets by far. ${ }^{6}$ The introduction of an eco-label will have little or no effect on the environment under such circumstances, because a certification of existing power plants would just result in a "virtual" attribution of some green electricity to specific user segments. Customers would improve their individual environmental record, but only in proportion to a decline of the environmental record of other households or firms.

As consumers state a clear preference for making a contribution to an improved electricity system, additional criteria for promoting new capacity have been defined by many labeling initiatives. Most of them demand minimum quota for new plants to be built in the context of marketing green power products. Another possibility to engender environmental improvements is an ecological upgrading of existing RES power plants, e.g. in the case of hydropower (see Naturemade, 2000).

How the ultimate effect of green power purchases may be determined depends crucially on the kind of assumptions and scenarios one chooses for the development of certain technologies. An expansion of new capacity will be all the more effective, if the supported technologies are able to reap learning economies as a consequence of the expansion of the green power market. The increased willingness to pay of green power customers would then operate as an innovation promotion tool and will speedup competitiveness of RES. The amount of actual innovation support, will depend on the governmental policies in place. In a country with a strong promotion policy, the role of the green power market

\footnotetext{
${ }^{6}$ In Germany, for example, the 1999 green electricity sales were about $90 \mathrm{GWh}$ in comparison to power generation from wind energy $(5500 \mathrm{GWh})$, small hydropower $(5600 \mathrm{GWh})$, biomass $(1100 \mathrm{GWh})$ and photovoltaics (20 GWh) (cf. Markard et al., 2000b).
} 
will probably be weaker than in a country without such a policy.

\subsection{Support and quality control}

All the intricate details of different criteria sets, probably will not be penetrable for the majority of the customers. Instead of personally deciding about the optimal criteria list, they will be happy to delegate the information seeking, valuing and assessment decisions to a trustworthy institution (Haberer, 1996). The crucial resource of such a body is its credibility. In the domain of environmental standards, environmental NGOs profit from a high trustworthiness. Alternatively, science-based institutes, consumer organizations or technical test laboratories may be accepted as intermediaries by the consumer, as well. In general, intermediaries will be more accepted if they are perceived as being independent from the immediate interests of the marketers. Moreover, a broad involvement of different stakeholders may further increase credibility and lower the risk of fundamental opposition against a labelingconcept.

Standards have, however, not only to be accepted by the consumers, but also by the producers. A pure NGObased label will have less success in the market place, if it is not accepted by the electric utilities. In complex products sectors like sustainable wood product, marine fishery, organic food, labels have been most successful, which were developed in a joint effort uniting representatives of the environmentally motivated firms and environmental NGOs.

Credibility of the label will also depend on the ability of the labeling organization to guarantee for the application of the criteria to the products according to a transparent and objective procedure. Quality control is delegated to professional auditors, which certify the compliance to the demanded criteria. Although the quality control of the label is often a highly sophisticated procedure, transparency should be maintained wherever possible. Customers should, in principle at least, be able to understand and even verify the criteria. In the context of marketing activities, customers who are interested should be able to visit the power plants for which they have signed their electricity contracts.

Transparency and credibility are key for the success of green electricity markets. Nevertheless, some tradeoffs have to be considered here, as well. The inclusion of different stakeholders in the development process of criteria may prove to be extremely time consuming and cumbersome. Compared to a label, which is supported by a single interest group, value judgements have to be made explicit and a common understanding has to be developed. This procedure is important, but carries high risks. At the level of quality control, the definition of an explicit auditing procedure by a professional auditor will, in general, be more costly.

\section{Analyzing eco-labeling in practice}

Having developed the dimensions in which labels may differ, we will now pass to an empirical analysis of six certification schemes from Europe. Additionally, we have included the US-American Green-e label. At first, a short description of each initiative as well as a tabular overview is provided showing that each label represents a specific approach to the issue (Table 1).

One of the first initiatives in Europe was the Swedish "Brå Miljøval" eco-label. It is owned and operated by the Swedish Society for Nature Conservation (SSNC), a Swedish environmental NGO. Brå Miljøval first set up criteria for green power in 1996 (SSNC, 1995). In 1999, the sales of certified green electricity were $8.9 \mathrm{TWh}$ which is about $6 \%$ of the Swedish national electricity demand (Eiderstrom, 2000). For 2000, the label acknowledged 70 licenses, including all major utilities. Since 1998, the label has been expanded to Norway and Finland.

In Germany, competition between different stakeholder groups led to the launching of three different labeling initiatives. The first in the certification of green power products was the association of German TÜVs (VdTÜV, 1998) in late 1998. The different regional TÜVorganizations are traditional auditing and technical supervision companies in Germany. Meanwhile, they have developed five different criteria catalogues for enduser products, two other for generation plants and one for certifying green power customers. In 2000, the TÜV companies certified more than 30 products, including hydropower products from Austria and Switzerland. Besides the TÜV, a private association "Grüner Strom Label" had been founded by environmental organizations and associations for the promotion of RES in 1999 (Eurosolar, 1999). The Grüner Strom Label certified two products so far, including an umbrella organization of 18 municipal utilities. Finally, an institute for applied research on ecology developed a certification scheme and launched a green power label (Öko-Institut, 1999). ÖkoInstitut, together with a consumer organization and the German World Wide Fund for Nature (WWF) founded a private organization "EnergieVision". In a pilot-phase four products have been labeled.

Green power products in the UK can apply for an accreditation within the "Future Energy" scheme, run by the Energy Savings Trust, which is supported by the British Government (EST, 1999). The Future Energy scheme distinguishes two types of green power offerings: renewable energy supply and renewable energy funds. By mid-1999, accreditation has been awarded to 13 products from 12 suppliers (Elliott, 2000). 


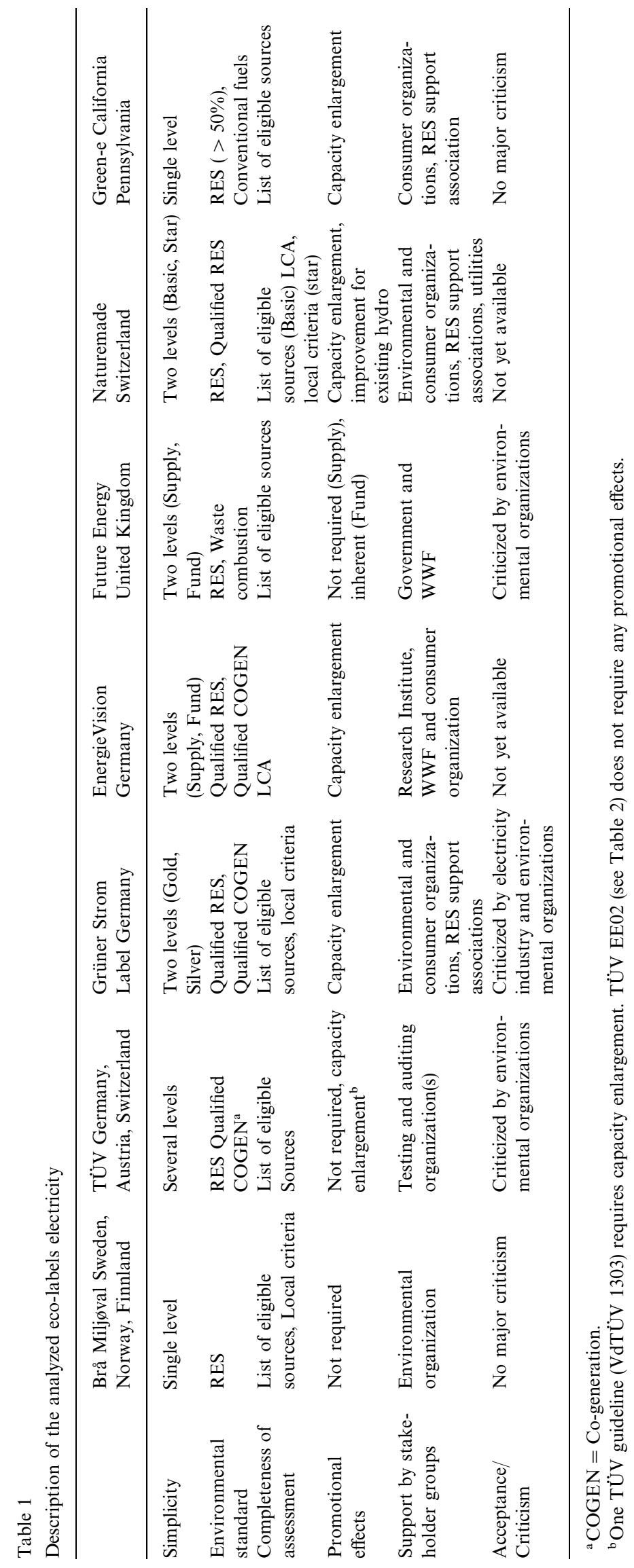


In Switzerland a two-level labeling scheme for green electricity has been launched following a broad stakeholder process: "naturemade basic" and "naturemade star". In a pilot-phase the evaluation procedure has been applied to more than 10 marketers and the first certificates have been delivered in November 2000 (Naturemade, 2000). The label is supported by electricity producers and suppliers, major environmental organizations and consumer representatives.

The Green-e label has been introduced in California in 1997 and has meanwhile certified 23 green power products of 14 power marketing companies (Wingate et al., 2000). A geographical rollout of the program is foreseen, e.g. to the Mid-Atlantic and New England states. First state of adoption was Pennsylvania in 1998.

\subsection{Comparison of eco-labels}

On the one hand, the described labeling schemes have main goals and principles in common like enhancing market transparency or strengthening customer demand for green electricity. All initiatives but two in our sample are specific labels, which have been explicitly founded for green electricity. The exceptions are Brå Miljøval, which is a label for green products in general and the German TÜV, who uses its seal for technical certification of machines and appliances also. Furthermore, the majority of eco-labels rely on professional, external auditors to manage the quality control of the certified products. Only the TÜV-concept is based on internal auditing, i.e. criteria setup, certification and control are executed by the same organization.

On the other hand, the individual labeling initiatives turn out to have fundamental differences, which will be compared according to the dimensions described in the previous section (see Table 1 for the details)

First, the simplicity and the environmental standards differ between the labels. In some eco-labels different environmental quality standards are applied to the certification levels introduced. Grüner Strom Label, for example, distinguishes pure RES products (Gold) and RES including co-generation (Silver). Naturemade certifies RES, in general, with its basic level and reserves the star level for ecological leaders among RES. EnergieVision and Future Energy separate products, which are based on a green power supply from products like ecofunds, which rely on conventional power supply but include promotional effects for RES. Green-e and Brå Miljøval, finally, opted for a single level eco-labeling approach. The TÜV has a simple seal, which represents a bewildering variety of guidelines.

With regard to the completeness of the assessment of potential environmental impacts, most eco-labels just use a list of eligible sources. Only EnergieVision and Naturemade star have defined their criteria on the basis of a life cycle assessment. Naturemade star is even more encompassing as it combines LCA with a set of minimum criteria for local environmental impacts. ${ }^{7}$

The promotional effects of green power products have been dealt with differently by the individual labeling initiatives. Grüner Strom Label, EnergieVision, Naturemade and Green-e set minimum shares for new power plants. Naturemade also accepts the improvement of the eco-performance of existing hydropower plants as a promotional effect. Future Energy does not explicitly include requirements for promotional effects. Still, renewable energy funds, which are approved under the label include investments in new capacity by definition. According to the TÜV concept green power suppliers can choose whether they want to integrate promotional effects or not. Brå Miljøval does not require any capacity enlargement or promotion at all.

The support by stakeholder groups, i.e. the kind of constituency of a labelling initiative is a decisive factor for generating credibility for the labeled products. ${ }^{8}$ Most of the existing labels are either supported (Grüner Strom Label, EnergieVision and Naturemade) or directly operated by environmental organizations (Brå Miljøval). Moreover, Grüner Strom Label and especially Naturemade seek for a broader stakeholder support including RES producer associations or consumer organizations. Only the Energy Savings Trust, the holding organization of the British Future Energy scheme depends on public funding.

Another key issue is the acceptance, respectively, criticism of the label by other stakeholder groups than those officially supporting the labeling initiative. In the case of Future Energy for instance, the declaration of waste incineration as a renewable energy source caused criticism by Friends of the Earth, a major UK environmental NGO (Elliott, 2000). Also, the TÜV is explicitly opposed by environmental organizations. They claim that the TÜV-label seems to promise environmental benefits, which most certified products cannot keep. The concept of Grüner Strom Label is criticized by environmental organizations and the electricity industry for excluding suppliers who are engaged in the conventional power business as well.

\footnotetext{
${ }^{7}$ The different approaches are especially visible in the case of hydropower: Naturemade star is based on a comprehensive evaluation procedure. Other schemes rely on single criterion approaches like "smaller than $10 \mathrm{MW}$ " or "built before 1995", for further details see: Markard et al. (2000b). The US label Green-e started with a short-hand criterion (30 MW for run of river plants). However, due to negative experiences with the approach they are about to adopt an assessment procedure, which is based on an encompassing local criteria list also (LIHI, 2000).

${ }^{8}$ For a description of the different interests and stakeholder positions see Markard et al. (2000a).
} 


\subsection{Identification of general labeling strategies}

In order to compare the seven examples in a qualitative way, we have divided each of the six dimensions into three ordinal categories [1-3], which range from low to high contribution to the core functions of the label. The dimensions have been set up as follows:

- Simplicity of the label: More than two levels differentiated [1], two levels [2], only single level [3].

- The environmental standard of labeled products: The products are just better than average [1], are restricted to RES incl. qualified forms of co-generation [2], or are only the "best" RES included [3].

- The completeness of the assessment: The criteria are given as a list of eligible sources [1], further criteria are applied for selected energy sources [2], an LCA (perhaps even including local criteria) is included [3].

- The promotional effects: No criteria for promotion required [1], indirect promotion [2], explicit promotion [3].

- The support of stakeholder groups: The eco-label is supported by one group[1], by two[2], or more than two different interest groups [3].

- The acceptance/criticism of the label: The label is criticized by two or more different stakeholder groups [1], by one kind of interest groups [2], or faces no major criticism, i.e. it is accepted by the major actors in the electricity market [3].

The scores of the seven different labels are represented in Table 2.

Before we may proceed to analyze the table, some methodological qualifications have to be made: The dimensions Simplicity, Support and Acceptance apply to the label as a whole. The other dimensions have to be differentiated according to the levels of each label. In the following argument, we have chosen some extreme cases (esp. TÜV-level "EE02" and Naturemade level "star"). This selection may seem unfair in some cases. Our purpose is, however, not to distinguish "good" from "bad" labels, but to illustrate the fundamental approaches and their associated tradeoffs.

We have grouped the individual dimensions into two categories. The environmental standard, completeness of assessment, promotion and support add up to a measure of overall credibility (column 6 of Table 2). Simplicity and acceptance, on the other hand, are summarized and attributed to a category representing the costs of a label (column 9 of Table 2). We have to admit, however, that our measure for cost is somewhat incomplete as no evaluation of the costs for obtaining the label (assessment of criteria, license fees, etc.) could be included, due to a lack of data.

As an overall measure for the quality of a label, we finally define the sum of all single scores (cf. last column of Table 2). According to this measure, three labels score high (Naturemade, EnergieVision and Grüner Strom Label), two labels range in the middle (Green-e and Brå Miljøval) and two labels score rather low (TÜV, Future Energy).

This simple scoring exercise may also be discussed with regard to credibility and costs. The credibility index distinguishes quite sharply between the three high scoring labels (Naturemade, EnergieVision and Grüner Strom Label) and the rest. In theses labels, consumers are perceived as wanting to be assured that no major environmental impacts are associated with the products they buy. They also represent approaches, which have been developed in multi-stakeholder processes and are therefore likely to encounter less criticism by other stakeholder groups.

However, credibility comes at a cost. The three highcredibility labels score only middle with regard to costs. The two first mover labels in the US and Europe (Green-e

Scorers of the analyzed eco-labels for electricity

\begin{tabular}{|c|c|c|c|c|c|c|c|c|c|}
\hline & \multicolumn{5}{|l|}{ Credibility } & \multicolumn{3}{|l|}{ Costs } & \multirow{2}{*}{$\begin{array}{l}\text { Sum } \\
\text { Total }\end{array}$} \\
\hline & $\begin{array}{l}\text { Environmental } \\
\text { standard }\end{array}$ & $\begin{array}{l}\text { Complete-ness } \\
\text { of the } \\
\text { assessment }\end{array}$ & $\begin{array}{l}\text { Promotional } \\
\text { effects }\end{array}$ & $\begin{array}{l}\text { Supported by } \\
\text { stakeholder } \\
\text { groups }\end{array}$ & Total & Simplicity & $\begin{array}{l}\text { Acceptance } \\
\text { criticism }\end{array}$ & Total & \\
\hline TÜV EE02 & 1 & 1 & 1 & 1 & 4 & 1 & 2 & 3 & 7 \\
\hline Future Energy & 1 & 1 & 2 & 1 & 5 & 2 & 2 & 4 & 9 \\
\hline Brå Miljøval & 2 & 2 & 1 & 1 & 6 & 3 & 3 & 6 & 12 \\
\hline Green-e & 1 & 1 & 3 & 2 & 7 & 3 & 3 & 6 & 13 \\
\hline $\begin{array}{l}\text { Grüner Strom } \\
\text { Label Gold }\end{array}$ & 3 & 2 & 3 & 3 & 11 & 2 & 2 & 4 & 15 \\
\hline $\begin{array}{l}\text { Energie Vision } \\
\text { Supply }\end{array}$ & 3 & 3 & 3 & 2 & 11 & 2 & $(2)^{\mathrm{a}}$ & 4 & 15 \\
\hline Naturemade star & 3 & 3 & 3 & 3 & 12 & 2 & $(2)^{\mathrm{a}}$ & 4 & 16 \\
\hline
\end{tabular}

\footnotetext{
${ }^{\mathrm{a}}$ Acceptance not yet available, average value chosen.
} 
and Brå Miljøval) have very favourable cost characteristics. They had been designed as simple labels, which encounter high acceptance in their respective home markets. Finally, the two remaining labels (TÜV and Future Energy) score medium to low on the cost dimension as they encounter substantial criticism in their home markets and do not score high with regard to simplicity. ${ }^{9}$

The cost of the label for the producer is directly linked to the complexity of the criteria and the associated procedure to test the criteria. But also indirectly, complexity of the label results in high development costs, which are likely to increase license fees. This argument is particularly important in an early phase of market penetration. The one label which is able to enter the market first is likely to "set the standard" for all laggards. So, there have been quite high opportunity costs for more complex approaches especially in countries with competing labeling initiatives. As a matter of fact, simple labels had been able to position themselves in the market early on (Green-e, Brå Miljøval, TÜV). With time, however, these initiatives realized shortcomings of their approaches and considered more complex and complete criteria lists: Green-e, for instance, is about to introduce a local criteria list for hydropower plants (LIHI, 2000) and Brå Miljøval wants to implement a more thorough evaluation of hydropower too. Future Energy currently reviews its criteria with regard to the criticism of environmentalists about the inclusion of energy from waste technologies. The TÜV follows a strategy of continuously creating new guidelines to cover newly emerging needs.

Summarizing, the individual labeling approaches have found specific ways to deal with the tradeoffs, we discussed in Section four. The resulting concepts depend on:

- How are customers' expectations represented in the criteria setup?

- Which interest groups are involved in the development of the criteria and how are the respective value judgements made?

- What role is attributed to the label in the context of the specific national energy policy?

Depending on the three questions above, our empirical cases seem to follow one of two basic strategies: Ecolabels are either designed to differentiate conventional electricity offerings and products being just better than average. The focus of those labels is rather "to assure that customers get what they paid for" (i.e. that the product meets the marketer's claims) than "to identify and support products which are environmental leaders". As a matter of fact, the label can rely on short-cut evaluation

\footnotetext{
${ }^{9}$ Although the TÜV seems to present a simple label to the consumers, the concept does not reduce complexity at all because of its high number of different criteria guidelines.
}

criteria and a concept, which is simple and easy to understand. In most cases, stakeholder involvement is kept to a minimum. The second strategy is to integrate stakeholder groups with divergent interests.

In the beginnings, the first strategy may be successful because it helps setting standards early in the market and keep costs of the label low. Furthermore, the supply of labeled products can grow rapidly as long as many products and generation technologies are eligible. Due to shortcomings concerning the environmental assessment or weak stakeholder involvement, the concept risks to encounter criticisms from consumers sooner or later.

The broadly based and balanced strategy, on the other hand, has considerable advantages in the medium and long term, when public awareness rises and consumers ask for more encompassing information about the environmental consequences of their product. Such eco-labels may be well suited as long-lasting environmental standards for the market as a whole. The simple concepts represent more of a "test and adapt" strategy in the early phases of market development.

\section{Conclusion and outlook}

Eco-labeling of electricity is an important means to empower consumers to freely express their preferences by reducing search and evaluation costs. We argued in the present paper that the substantiation of this goal leads into a host of complex issues, which reflect the complexity of electricity generation and consumption as a whole. Key dimensions for the development of an eco-label for electricity as well as fundamental tradeoffs could be identified: the simplicity of the labeling design, the completeness of the assessment procedure, the environmental standard chosen, the promotional effects demanded and the way different stakeholder groups are included. These dimensions could be verified quite well at the level of the individual labeling approaches. Much more difficult was the assessment of cost terms. The market has not developed enough to compare the different approaches accurately. Our analysis showed, that two basic strategies had been chosen to deal with the above-mentioned dimensions. Either a label which is simple and has rather low or medium environmental standards or an eco-label which aims at representing the entirety of environmental impacts associated with a product. In an early phase, the quicker labels have a considerable advantage to set the standard in the market. In the medium and long term, however, public awareness will rise and consumers will ask for encompassing information about the environmental consequences of their product.

This analysis may be of interest to other regions in the world where electricity markets are about to be liberalized and where quality assurance for green power products 
will become an issue of public interest. In Europe the question will be (i) what many and which of the existing labels will survive in the long run and (ii) what an ecolabel should look like for the common European electricity market. As the market for green power grows and EU wide trade in electricity expands, transparency and credibility of environmental quality claims will increase in importance.

Based on the analysis of our paper, we may describe a rough road map for the development of a European label:

- First, promoters of a European label should define common goals and a common conceptual approach. The integration of different actors representing different interests will turn out to be a crucial precondition for success.

- In the second step, basic definitions and value judgements would have to be agreed on.

- Finally and probably most importantly, different national backgrounds will have to be taken into consideration: the existing national power generation mix, the structure of the electricity industry, current use and future potential of RES in the member states, prevalent environmental impacts, social and political preferences and so on.

A possible strategy for resolving the third problem may be to agree on basic principles and a common concept, while applying the subsidiary principle to regulate the details of certification in different national contexts. (Markard and Truffer, 1999). Electricity traded under the European label would also have to be recognized by other schemes, which join the system. Furthermore, there is a considerable potential to enhance efficiency and speed up the development process if the European label would be based on (at least some of) the existing approaches. A European label could function as a common platform, which could coordinate the decentralized initiatives and knowledge pools. European policy could help here to start such stakeholder processes in order to arrive at a broadly shared standard for what might count as environmentally preferable electricity products.

\section{Acknowledgements}

The authors would like to thank the anonymous reviewer for his valuable comments. The responsibility for remaining errors is with the authors.

\section{References}

Akerlof, G.A., 1970. The market for 'lemons': quality uncertainty and the market mechanism. Quarterly Journal of Economics 84, 488-500.
De Jasay, A., 1989. Social contract, free ride: a study of the public goods problem. Oxford University Press, Oxford.

Eiderstrom, E., 2000. Swedish society for nature conservation - good environmental choice electricity. Paper Presented at the NGO Workshop on European Green Electricity Label, Brussels, March $15-16$.

Elliott, D., 2000. Prospects for the green power market in the UK. Proceedings of the World Renewable Energy Congress VI, Brighton, pp. 1428-1432.

EPA, 1998. Environmental labeling. Issues, policies, and practices worldwide. United States Environmental Protection Agency (EPA), EPA 742-R-98-009, Washington DC.

EST, 1999. Future energy - a scheme for accrediting renewable energy. Scheme description and criteria. Issue 1, Energy Saving Trust (EST), London.

EUROSOLAR, 1999. Kennzeichnungskriterien für das Label als Grüner Stromanbieter, Der Markt für Grünen Strom, EurosolarVerlag, Bochum.

Farhar, B.C., 1999. Willingness to pay for electricity from renewable resources: a review of utility market research. National Renewable Energy Laboratory, NREL/TP.550.26148, Golden, July 1999.

Fouquet, R., 1998. The United Kingdom demand for renewable electricity in a liberalised market. Energy Policy 26, 4, 281-193.

Frischknecht, R., Jungbluth, N., 2000. Globale Umweltkriterien für Ökostrom, ESU-services, Zürich

FSC, 2000. Forest Stewardship Council (FSC) United States. See http://www.foreststewardship.com.

Future Energy, 1999. A scheme for accrediting renewable electricity. Scheme description and criteria. Issue 1, Energy Savings Trust, London.

Goedkoop, M., 1995. The eco-indicator 95: weighting method for environmental effects that damage ecosystems or human health on a European scale. PRé Consultants, Amersfoort, NL.

Haberer, A., 1996. Umweltbezogene Informationsasymmetrien und transparenzschaffende Institutionen. Metropolis-Verlag, Marburg.

Holt, E., 1997a. Green pricing resource guide. The regulatory assistance project, Gardiner, Maine.

Holt, E., 1997b. Disclosure and certification: truth and labeling for electric power. Issue Briefs No. 5, Renewable Energy Policy Project, University of Maryland, College Park.

Jegen, M., Wüstenhagen, R., 2000. Modernise it, sustainabilise it! Swiss energy policy on the eve of electricity market liberalisation. Energy Policy 29 (1), 45-54.

LIHI, 2000. Low impact Hydropower Institute. See http://www.lowimpacthydro.org/.

Loskow, P.L., 1998. Electricity sectors in transition. The Energy Journal 19 (2), 25-54.

Lovins, A.B., Lovins, H.L., Hawken, P., 1999. A road map for natural capitalism. Harvard Business Review, 77, 145-158.

Markard, J., 1998. Green-pricing - Welchen Beitrag können freiwillige Zahlungen von Stromkunden zur Förderung regenerativer Energien leisten?, Werkstattreihe Nr. 104, Öko-Institut-Verlag, Freiburg.

Markard, J., Rothenberger, D., Truffer, B., 2000a. Analysing market mechanisms of third party eco-labeling: the case of green power certification. Paper Presented at ESEE conference, Vienna, May 3-6.

Markard, J., Truffer, B., 1999. Der lange Weg zu einem Euro-Label für Strom. Energiewirtschaftliche Tagesfragen 49 (11), 724-728.

Markard, J., Truffer, B., Bratrich, C., 2000b. Ecological and competitive green electricity from certified hydropower plants in liberalized electricity markets. Hydro 2000 - Making Hydro more Competitive, Conference Proceedings, The International Journal on Hydropower \& Dams, Sutton, pp. 717-725.

Mayer, R., Blank, E., Swezey, B., 1999. The grassroots are greener: a community-based approach to marketing green power. Research Report No. 8, Renewable Energy Policy Project, University of Maryland, College Park. 
Morris, J., 1997. Green Goods? Consumers, product labels and the environment. IEA Studies on the Environment No. 8, The Institute of Economic Affairs, London.

Naturemade, 2000. Informationen zum Qualitätszeichen naturemade basic. Version 2.0, Verein für unweltgerechte Elektrizität, Zurich.

NCCEI, 1998. Synthesis Report: A Summary of Research on Information Disclosure. Draft National Council on Competition and the Electricity Industry (NCCEI). The Regulatory Assistance Project, Gardiner, Maine.

Oberholzer-Gee, F., 2000. Your contribution counts! an empirical analysis of the decision to support solar energy. Paper Presented at the Wharton Impact Conference, Philadelphia, January.

Öko-Institut, 1999. Entwicklung eines Zertifizierungsverfahrens für "Grünen Strom", Endbericht, Öko-Institut, Darmstadt Freiburg Berlin.

Porter, M.E., 1980. Competitive Strategy. The Free Press, New York.

REA, 1998. Disclosure: A Vital Tool for Consumers. Renewable Energy Alliance (REA), Oakland. See also http://www.realliance.org.

Roper Starch Worldwide, 1998. The 1998 Green Gauge Reports, Executive Report. Roper Starch Worldwide, New York.

Russel, T., 1998. Greener purchasing. Opportunities and innovations. Greenleaf Publishing, Sheffield, UK.
Salzman, J., 1997. Informing the green consumer. The debate over the use and abuse of environmental labels. Journal of Industrial Ecology 1 (2), 11-21.

Schelling, T., 1998. The environmental challenges of power generation. The Energy Journal 19 (2), 115-124.

SSNC, 1995. Environmental criteria for electricity. Brå Miljøval. Swedish Society for Nature Conservation (SSNC), Göteborg.

Umweltbundesamt, 1998. Erfolgskontrolle Umweltzeichen. Texte NR. 61/98, German Federal Environmental Agency, Berlin.

VdTÜV, 1998. Bereitstellung von Strom aus Erneuerbaren Energien. Vergaberichtlinie für ein TÜV-Zertifikat. Energie- und Gebäudetechnik 1303. Verband der technischen Überwachungsvereine (VdTÜV), Essen.

Villiger, A., Wüstenhagen, R., Meyer, A., 2000. Jenseits der Öko-Nische. Birkhäuser Verlag, Basel Boston Berlin.

Wingate, M., et al., 2000. Green Power certification - environmental and consumer protection benefits of the Green-e programme. Renewable Energy World, 3(3), 63-73.

Wiser, R., 1999. The role of public policy in emerging green power markets: an analysis of marketer preferences, LBNL Report No. 44178. Lawrence Berkeley National Laboratory, Berkeley.

Wüstenhagen, R., 2000. Ökostrom - von der Nische zum Massenmarkt, vdf Hochschulverlag AG, Zurich. 